\title{
COSMC knockdown mediated aberrant O-glycosylation promotes oncogenic properties in pancreatic cancer
}

\author{
Bianca T. Hofmann ${ }^{1,4^{*}}$, Laura Schlüter ${ }^{1}$, Philip Lange ${ }^{1}$, Baris Mercanoglu ${ }^{1}$, Florian Ewald ${ }^{2}$, Aljonna Fölster ${ }^{1}$, \\ Aeint-Steffen Picksak', Sönke Harder ${ }^{3}$, Alexander T. El Gammal', Katharina Grupp', Cenap Güngör?', \\ Astrid Drenckhan ${ }^{1}$, Hartmut Schlüter ${ }^{3}$, Christoph Wagener ${ }^{3}$, Jakob R. Izbicki ${ }^{1}$, Manfred Jücker ${ }^{5}$, \\ Maximilian Bockhorn ${ }^{1+}$ and Gerrit Wolters-Eisfeld ${ }^{1+}$
}

\begin{abstract}
Background: Human pancreatic ductal adenocarcinoma (PDAC) is one of the most aggressive and lethal malignancies in the world and despite great efforts in research types of treatment remain limited. A frequently detected alteration in PDACs is a truncated O-linked N-acetylgalactosamine (GalNAc) glycosylation with expression of the Tn antigen. Changes in O-glycosylation affect posttranslationally modified O-GalNAc proteins resulting in profound cellular alterations. Tn antigen is a tumor associated glycan detected in 75-90\% of PDACs and up to $67 \%$ in its precursor lesions. Since the role of Tn antigen expression in PDAC is insufficiently understood we analyzed the impact of COSMC mediated Tn antigen expression in two human PDAC cell lines on cellular oncogenic properties.

Methods: Forced expression of Tn antigen on O-glycosylated proteins in pancreatic cancer cells was induced by lentiviral-mediated knockdown of the COSMC chaperone, which prevented O-glycan elongation beyond the initial GalNAca1- residue on O-linked glycoproteins. Altered O-GalNAc glycosylation was analyzed in human pancreatic cancer cell lines Panc-1 and L3.6pl using Western and Far-Western blot as well as immunocytochemical techniques. To assess the biological implications of COSMC function on oncogenic properties, cell viability assays, scratch assays combined with live cell imaging, migration and apoptosis assays were performed. Lectin based glycoprotein enrichment with subsequent mass spectrometric analysis identified new cancer O-GalNAc modified proteins. Expression of Tn antigen bearing Nucleolin in patient derived PDAC tumor specimens was evaluated and correlated with clinicopathological data.

Results: Tn antigen expression was induced on various O-GalNAc glycoproteins in COSMC deficient cell lines compared to the control. Proliferation was reduced $(p<0.001)$ in COSMC knockdown cells, whereas migration was increased $(p<0.001)$ and apoptosis was decreased $(p=0.03)$, highlighting the importance of Tn antigen expression on metastatic and anti-apoptotic behavior of PDAC derived cells. Nucleolin was identified as O-GalNAc modified protein in COSMC deficient PDAC cell lines. Interestingly, immunohistochemical staining and co-localization studies of patient derived PDACs revealed poor survival for patients with strong co-localization of Tn antigen and Nucleolin $(p=0.037)$.

Conclusion: This study substantiates the influence of altered O-glycan (Tn/STn) expression on oncogenic properties in pancreatic cancer and identifies O-GaINAc modified Nucleolin as novel prognostic marker.
\end{abstract}

Keywords: Pancreatic cancer, PDAC, O-GalNAc, O-glycosylation, Tn antigen, COSMC, C1GALTC1, Nucleolin

\footnotetext{
* Correspondence: bi.hofmann@uke.de

${ }^{\dagger}$ Equal contributors

'Department of General, Visceral and Thoracic Surgery, University Medical Center Hamburg-Eppendorf, Martinistrasse 52, 20246 Hamburg, Germany ${ }^{4}$ Department of Anatomy and Experimental Morphology, University Medical Center Hamburg-Eppendorf, Martinistrasse 52, 20246 Hamburg, Germany Full list of author information is available at the end of the article
} 


\section{Background}

Changes in O-GalNAc glycosylation (N-acetylgalactosaminyl glycosylation; hereafter referred simply as Oglycosylation) are typical characteristics of malignant transformation in epithelial cells [1]. Given the complexity of protein glycosylation and its superordinated impact on a diverse range of biological processes it is not surprising that seemingly minor alterations in carbohydrate structure can significantly impact cell biology. Current research on differential O-glycosylation starts to elucidate its influence on carcinogenesis and malignant transformation. For instance, O-glycosylation of DR4/DR5 death receptor regulates apoptosis resistance or sensitivity [2] and aberrant $\mathrm{O}$-glycosylation of $\beta$-integrins alters the cellular phenotype and influences proliferation and haptotaxis [3]. Recently, Radhakrishnan et al. demonstrated the impact of truncated O-glycans on cell-cell adhesion and migration in pancreatic cancer [4].

The Tn antigen (GalNAca1-O-Ser/Thr) is a frequently occurring aberrant $\mathrm{O}$-glycan expressed at high levels in many cancers [5] including pancreatic ductal adenocarcinoma (PDAC) [6-8], PDAC precursor lesions [7] and is detectable in PDAC sera $[9,10]$. Expression of Tn antigen and its sialylated form sialyl-Tn (STn) antigen is associated with poor survival $[11,12]$ and promotes oncogenic features [4]. Tn antigen expression is initiated by polypeptide $\mathrm{N}$-acetylgalactosaminyltransferases (GalNAc-Ts), which connect GalNAc residues with the target protein as a posttranslational modification. In humans, 20 different GalNAc-Ts are identified so far, leading to a complex interplay of various enzymes reflected in the cellular O-glycobiome. Tn antigen is further processed by core 1 synthase (C1GALT1 or T-synthase), which transfers Galactose (Gal) to GalNAc-Ser/Thr to form the $\mathrm{T}$ antigen, also referred as core 1 structure. COSMC (C1GALT1C1) is the unique chaperone of T-synthase and is essential for its functional formation in order to elongate glycans beyond the initial Tn structure (Fig. 1a) [13]. Dysfunctional COSMC is also able to convert a wild type protein into a tumor-specific antigen [14] affecting tumor cell biology.

Several factors are known to contribute to the formation of Tn/STn antigen on glycoproteins. Major factors are altered levels in COSMC and/or T-synthase gene expression as well as differential expression and localization of GalNAc-transferases. In detail, acquired mutations in COSMC [13, 15], epigenetic silencing of COSMC and/or T-synthase, including hypermethylation of the COSMC promotor $[4,16]$ as well as altered signaling pathways and altered expression or localization of GalNAc-transferases [17-22] may contribute to Tn and/or STn expression.

$\mathrm{Tn} / \mathrm{STn}$ antigens are cancer-associated glycans recognized by the human macrophage galactose binding glycoreceptor MGL (CLEC10A/CD301) [23-25] that is expressed on immature and tolerogenic dendritic cells and macrophages. Since Tn/STn glycans and glycopeptides are not or poorly immunogenic, vaccination based cancer therapy remains challenging. Nonetheless, the attempt of generating Tn specific antibodies with in vivo anti-tumor activity was described [26, 27]. Preclinical animal studies showed promising immunogenicity, but none of the immuno conjugates succeeded in clinical trials, despite safe administration and proper immune responses [28]. Recent and ongoing vaccine trials are encouraging for future trials and the design of proper immunogens and immuno-conjugates remain the main challenge. Interestingly, $\mathrm{ABO}$ blood group IgM agglutinins/antibodies were observed to interact with PDAC O-GalNAc modified glycoproteins possibly affecting cancer onset [29].

Nevertheless, pancreatic carcinoma is one of the worlds' most aggressive malignancies [30] and consequences of COSMC mediated Tn antigen expression in pancreatic carcinoma are not fully understood. Investigation of Tn modified glycoproteins and its impact on oncogenic properties is crucial to understand tumor biology and potential therapeutic options.

\section{Results}

Differential expression of $\mathrm{Tn}$ antigen in human pancreatic carcinoma cell lines

Several PDAC derived cell lines were available for Tn antigen screening using Western and Far-Western blot analysis. Besides commercially available PDAC cell lines such as Panc-1, BxPC3, MiaPaca2 and L3.6pl, patient derived cell lines $\mathrm{PaCa} 5061$ [31], PaCa 5072 and $\mathrm{PaCa}$ 5167, and a Gemcitabine resistant sub-clone of the parental L3.6pl cell line, L3.6pl-res cells were used [32]. Analysis of Tn antigen expression in cell lysates was performed using distinct antibodies or glyco epitope recognizing lectins. Jurkat cells express mutated COSMC [13] and were used as Tn antigen positive control. Interestingly, PDAC cell lines displayed differential expression of the Tn antigen. Using the Tn antigen specific antibody MA1-90544, L3.6pl-Res and PaCa 5072 cells showed a strong positivity, whereas L3.6pl, PaCa 5061 and BxPC3 cells were weakly positive. Minimal signals were detectable in Panc-1, PaCa 5167 and MiaPaca2 cells (Fig. 1b). Similar results were obtained using VVL, HPA lectins and sialyl Tn antibody reflecting consistency (Additional file 1: Figure S1-S3).

In order to induce the expression of Tn antigen in the minimal Tn antigen positive Panc- 1 cell line and the moderate Tn antigen positive L3.6pl cell line, we performed a lentiviral-mediated knockdown of COSMC chaperone followed by single colony selection with puromycin. Knockdown of COSMC was highly efficient in Panc-1 cells, compared to cells transduced with a control 


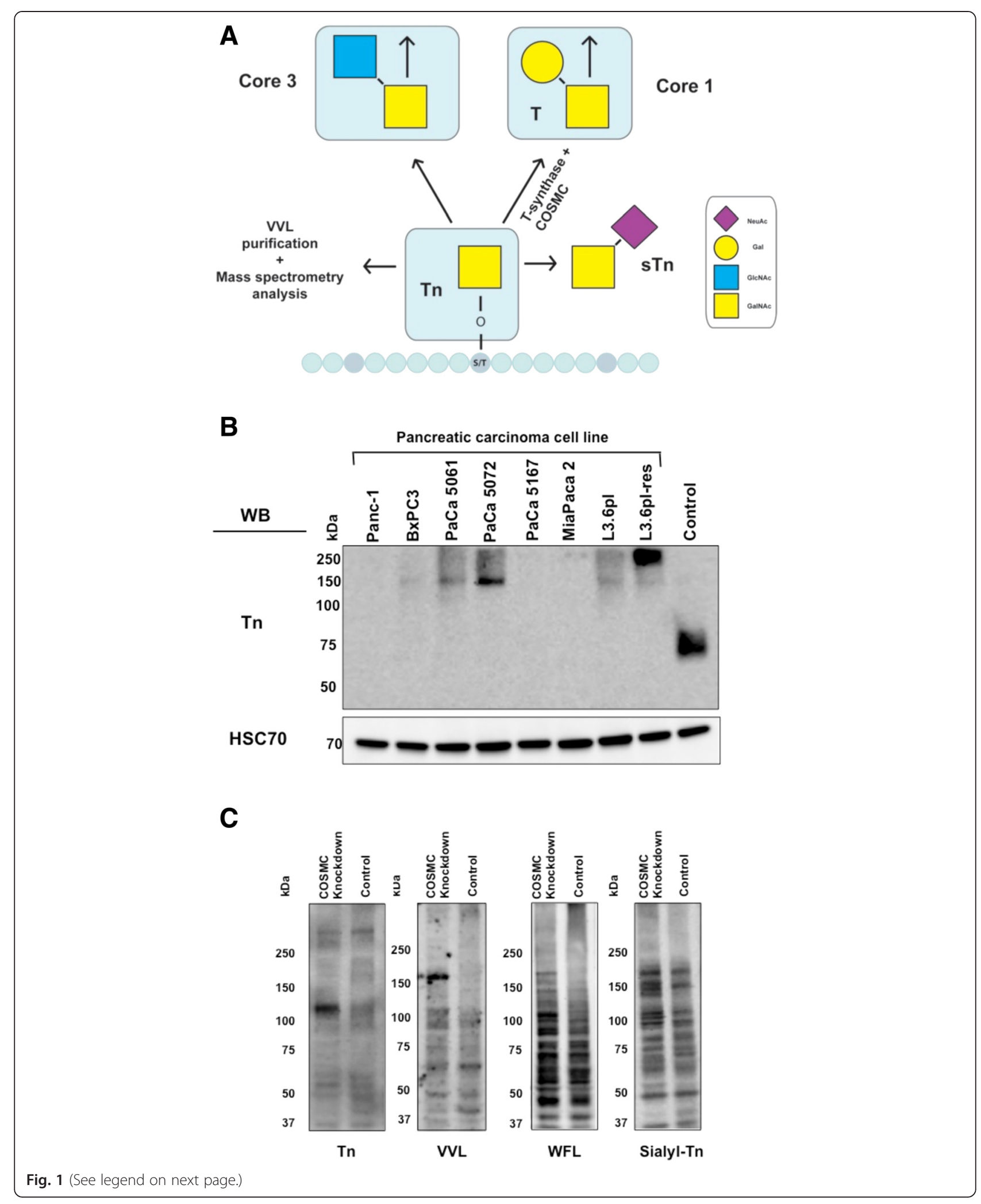


(See figure on previous page.)

Fig. 1 Expression of aberrant O-glycans in pancreatic cancer. a Biosynthesis of Tn antigen, sTn antigen and Core 1 and 3 structures. Tn antigen is composed of an O-glycosidic linked N-acetylgalactosamine (GalNAc) to the $-\mathrm{OH}$ group of serine/threonine (S/T). Tn antigen is either processed by core $1 \mathrm{~T}$-synthase (C1GalT1) and its chaperone (COSMC), which transfers a galactose (Gal) to GalNAc-serine/threonine to form the T antigen also referred as core 1 structure or processed by transfer of a $\mathrm{N}$-acetylglucosamine (GlcNAc) to form the core 3 structure. Tn antigen can also be modified by addition of a sialic acid (NeuAc). b Differential expression of Tn antigen in pancreatic carcinoma cell lines. Eight different PDAC cell lines were available for analysis. Western and Far-Western blot analysis of total cell lysates was performed using the Tn antigen specific antibody MA1-80055. Detection of HSC70 served as loading control. Jurkat cells were used as positive control for Tn antigen expression. c Expression of Tn antigen and aberrant O-glycans in COSMC knockdown cells. Western blot analysis showed a strong expression of aberrant O-glycans as well as Tn antigen in Panc-1 COSMC knockdown cells compared to control cells. Sialyl-Tn and Tn antibodies were used as well as lectins such as WL (Vicia villosa lectin) and WFL (Wisteria floribunda lectin)

vector (Additional file 1: Figure S4). Additionally, down regulation of COSMC was confirmed on mRNA level by real-time PCR, achieving $97 \%$ efficiency in Panc-1 and $73 \%$ in L3.6pl cells (Fig. 2b and d). Next, expression of atypical O-glycans was evaluated using different glyco epitope recognizing antibodies and lectins. Using sialyl-Tn and Tn antigen antibodies as well as VVL and WFL, revealed an enhancement of distinct staining patterns in COSMC knockdown cells compared to control cells (Fig. 1c). L3.6pl cells revealed an enhanced Tn antigen expression only after treatment with Neuraminidase (Additional file 1: Figure S5). Immunocytochemistry revealed an enhanced staining of VVL and WFL lectin in COSMC knockdown cells compared to controls (Additional file 1: Figure S6).

\section{Decreased expression of GalNAc-transferases in COSMC knockdown cells}

COSMC knockdown causes a cell type specific Tn antigen expression pattern mediated by the subset of expressed GalNAc-transferases. Since GalNAc-transferase 2 and 5 are already identified as O-GalNAc modified glycoproteins [33], a COSMC knockdown could influence GalNActransferase activity and consecutive GalNAc-T expression levels as a cellular response. This could result in an altered Tn antigen expression pattern caused by impaired GalNAc-T activity compared to the initially induced COSMC knockdown Tn antigen expression pattern. Since GalNAc-transferase activity assays are not available, we analyzed GalNAc-Ts expression levels in COSMC knockdown cells compared to controls. We used quantitative real-time PCR to evaluate expression levels of all known human GalNAc-Ts (1-20) in Panc-1 as well as L3.6pl COSMC knockdown cells and corresponding control cells. In seven out of 20 investigated GalNAc-T isoform mRNAs were readily detectable using real-time PCR and showed differential mRNA expression levels in COSMC knockdown cells. The GalNAc-T isoforms 1, 2, 7, 10, 11, 12, and 18 were expressed in Panc-1 cells (Fig. 2a). Interestingly, COSMC-depleted Panc-1 cells showed a substantial decrease in mRNA expression for all detected GalNAc-T isoforms, compared to the respective control cells. In fact, relative mRNA expression was decreased up to $50 \%$ $(p<0.001)$ (Fig. 2a). Also, analysis of mRNA expression levels of the $\mathrm{T}$ synthase, a key enzyme in the cellular O-glycan pathway, revealed a substantial increase in COSMC knockdown cells, compared to control cells (Fig. 2b). L3.6pl cells showed the expression of GalNAc-T isoforms 1, 2, 3, 7, 10, 11, 12, 14 and 18 (Fig. 2c). Except GalNAc-T 2, all other isoforms showed decreased mRNA expression in COSMC knockdown cells, comparable to the results of Panc-1 COSMC knockdown and control (Fig. 2c). In contrast, L3.6pl COSMC knockdown was approximately $80 \%$, and T-synthase levels did not display any differences (Fig. 2d). Next, T-synthase activity was measured in Panc-1 and L3.6pl cells. Panc-1 COSMC knockdown cells displayed $69.9 \%$ T-synthase activity and T-synthase activity in L3.6pl COSMC knockdown cells was $67 \%$, compared to control cells (Fig. 2e).

\section{MS-based identified Nucleolin, GRP-78, a-Enolase and Annexin A2 display O-GalNAc glycosylation}

Although several Tn antigen carrier molecules have been identified in various cancers, the molecular identity of these different O-glycosylated proteins still remains enigmatic. In order to identify new pancreatic cancer specific O-glycosylated proteins that express the Tn antigen, we applied lectin-based immunoprecipitation using VVL in COSMC knockdown as well as corresponding control cells (Additional file 1: Figure S7) accompanied by peptide identification via mass spectrometry. VVL is able to bind glycopeptides through single GalNAc molecules and its binding affinity was demonstrated to depend on Tn antigen cluster formation [34].

Among the top hits, we identified Nucleolin, GRP-78, Annexin A2 and $\alpha$-Enolase (Tab.1). A careful review of the literature revealed that Nucleolin and GRP-78 have previously been described to carry O-glycosylated residues $[33,35]$. These four candidates appeared to be promising, because these proteins i) are differentially expressed in pancreatic carcinoma [36-39], ii) are cell membrane localized (at least in carcinoma) [40-43] iii) and are known to promote cancer cell signaling. Moreover, in silico analysis of the identified peptide protein sequences using the isoform specific O-glycosylation prediction (ISOGlyP) database [44], revealed that these 


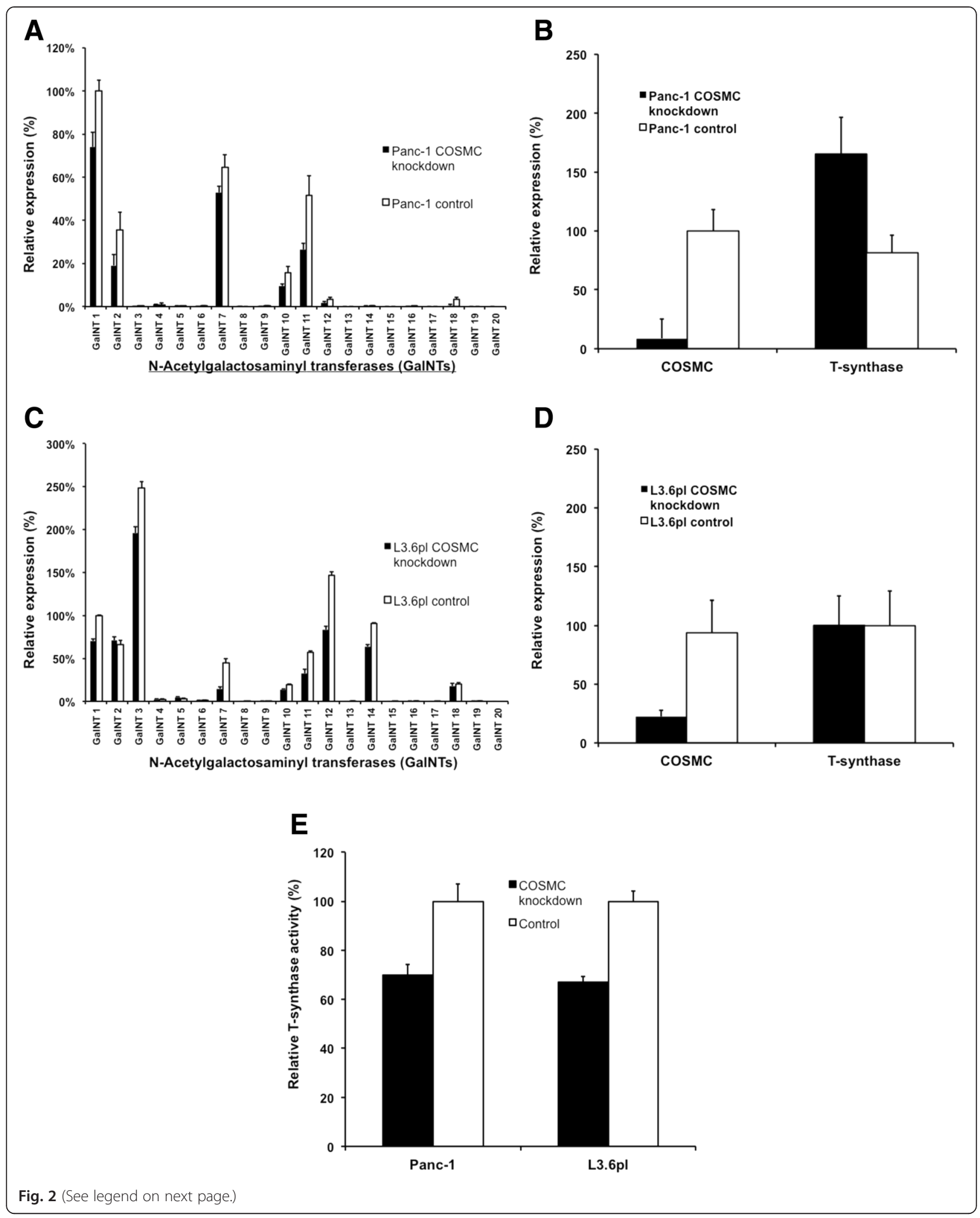


(See figure on previous page.)

Fig. 2 Aberrant mRNA expression levels of GalNAc-transferases, T-Synthase and COSMC as well as T-synthase activity in COSMC-depleted pancreatic cancer cells. a Relative mRNA expression of all human GalNAc-transferase isoforms in COSMC knockdown as well as control Panc-1 cells, quantified using real-time PCR. $\mathbf{b}$ Relative quantification of T-synthase mRNA expression in COSMC knockdown and control Panc-1 cells. Note: mRNA expression level of T-synthase is almost doubled in COSMC knockdown cells. c Relative mRNA expression of GalNAc-transferase isoforms in L3.6pl. d Relative quantification of T-synthase and COSMC mRNA expression in L3.6pl COSMC knockdown and control cells. e T-synthase activity was measured in Panc-1 and L3.6pl COSMC knockdown and control cells using GalNAc-a-4MU fluorescent assay

proteins are likely to be O-GalNAc glycosylated [33]. Referring to the results of GalNAc-transferase isoform expression of Panc-1 cells, isoforms T1 and T12 showed highest prediction possibility of O-GalNAc-glycosylation for Nucleolin. Highest prediction for GRP-78 showed GalNAc-transferase isoforms T2 and T12, for $\alpha$-Enolase T10 and T12 and for Annexin A2 T1 and T2.

For proof-of-concept, we confirmed the Tn expression on Nucleolin, GRP-78, $\alpha$-Enolase and Annexin A2 through VVL-based immunoprecipitation followed by detection of the target proteins with specific antibodies (Fig. 3a). Protein expression levels of the identified proteins in total cell lysates of COSMC knockdown as well as control cells remained unchanged, except for Annexin A2 which showed a decrease in Panc-1 COSMC knockdown cells (Fig. 3a). Vice versa immunoprecipitation with the protein specific antibody and detection with VVL lectin showed distinct staining patterns at indicated molecular weight (Fig. 3b). Additionally, we performed immunocytochemistry to investigate the intracellular localization of Tn antigen and Nucleolin using COSMC depleted Panc-1 cells. Interestingly, VVL mediated Tn antigen staining showed cell surface as well as a predominant cytoplasmic staining. The co-staining of Nucleolin in COSMC knockout Panc-1

Table 1 Mass spectrometry identified O-GalNAc modified proteins

\begin{tabular}{|c|c|c|c|c|}
\hline Protein & Gene & Uniprot acc. No. & NetOGlyc 4.0 & $\overline{\text { References }}$ \\
\hline Nucleolin & $\mathrm{NCL}$ & P19338 & +++ & {$[35]$} \\
\hline Alpha-1-acid glycoprotein 1 & AGP1 & P02763 & - & \\
\hline Alpha-actinin-4 & ACTN4 & 043707 & +++ & \\
\hline Ig alpha-1 chain C & $|\mathrm{GHA}|$ & P01876 & ++ & \\
\hline Elongation factor 2 & $\mathrm{EEF} 2$ & P13639 & ++ & \\
\hline GRP-78 & HSPA5 & P11021 & + & [33] \\
\hline HSP73 & HSPA8 & P11142 & + & \\
\hline PABP1 & PABPC1 & P11940 & ++ & \\
\hline PABP4 & PABPC4 & Q13310 & + & \\
\hline Alpha-enolase & ENO1 & Q6GMP2 & + & \\
\hline Elongation factor 1-gamma & EEF1G & P26641 & ++ & \\
\hline EF-1-alpha-like 3 & EEF1A1P5 & Q5VTE0 & + & \\
\hline Tubulin beta & TUBB2A & Q13885 & - & \\
\hline Galectin-12 & LGALS12 & Q96DT0 & ++ & \\
\hline Ras association domain-containing protein 2 & RASSF2 & P50749 & +++ & \\
\hline GAPDH & GAPDH & P04406 & + & \\
\hline Nucleophosmin & NPM1 & Q8WTW5 & +++ & \\
\hline Annexin A2 & ANXA2 & P07355 & + & \\
\hline $37 \mathrm{kDa}$ laminin receptor precursor & RPSA & Q86VC0 & +++ & \\
\hline Leucyl-cystinyl aminopeptidase & LNPEP & Q9UIQ6 & + & \\
\hline elF-5B & EIF5B & O60841 & +++ & \\
\hline Armadillo repeat-containing protein 4 & ARMC4 & Q5T2S8 & +++ & \\
\hline LanC-like protein 2 & LANCL2 & Q9NS86 & ++ & \\
\hline
\end{tabular}

Proteins identified from Panc-1 COSMC knockdown cells by immunoprecipitation using WL agarose accompanied by mass spectrometry. The O-GalNAc prediction tool (NetOGlyc 4.0) [52] was used to assess possibility of O-glycosylation. Score indicates percentage of possibly O-GalNAc modified Serin/Threonin residues $(+<10 \%,++<20 \%$, $+++>20 \%$ ). References are presented for previously identified O-GalNAc modified glycoproteins 

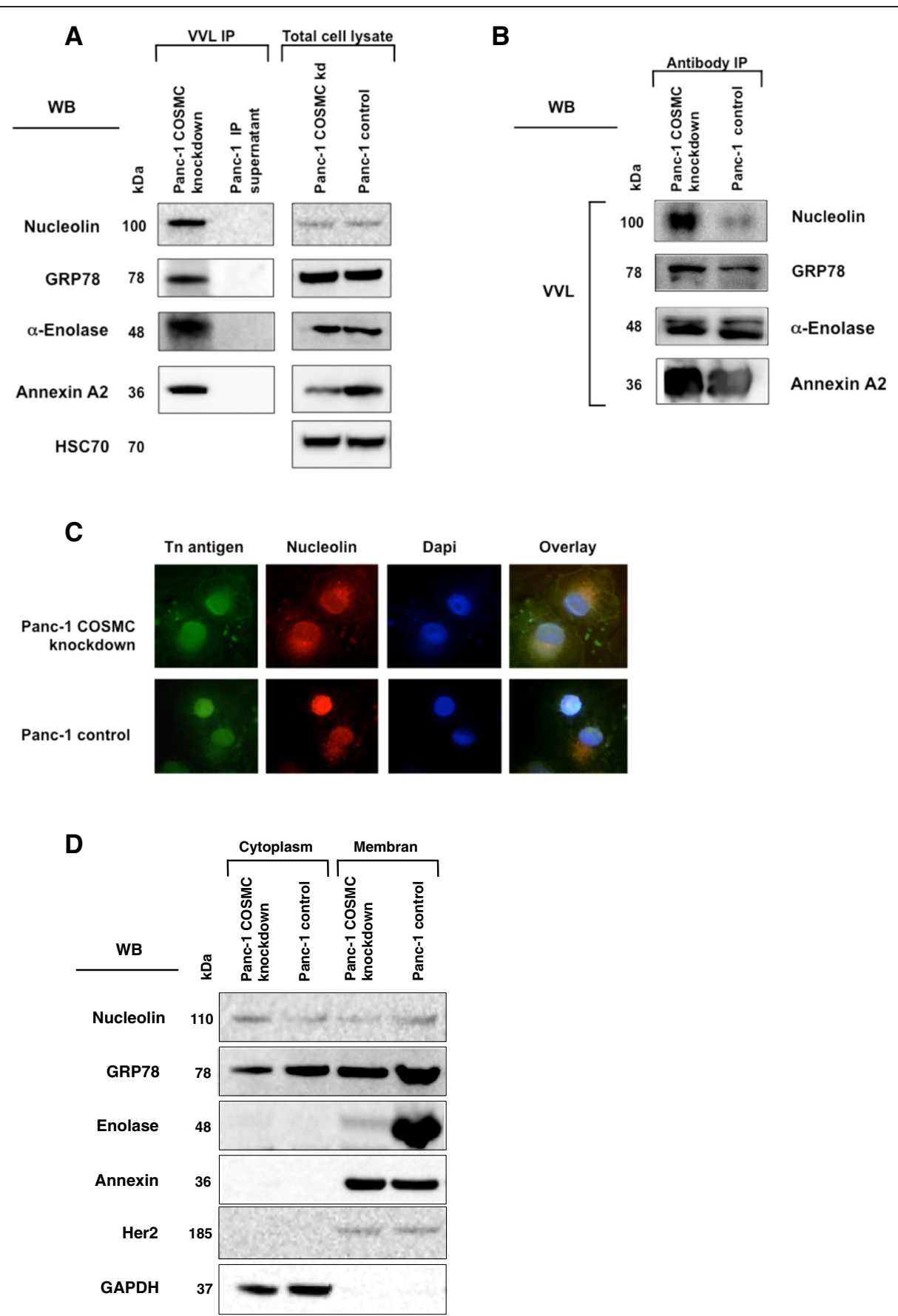

Fig. 3 MS identified Nucleolin, GRP-78, a-Enolase and Annexin A2 display O-GalNAc glycosylation. a left: Tn antigen is expressed on Nucleolin, GRP-78, a-Enolase and Annexin A2. Immunoprecipitation and western blot analysis were performed using WL lectin for Tn antigen precipitation and Nucleolin, GRP-78, a-Enolase and Annexin A2 antibodies for detection of specific protein signals. a right: Protein expression levels of the identified proteins in total cell lysates of COSMC knockdown as well as control cells remained unchanged, except for Annexin 2, which showed a decrease in Panc-1 COSMC knockdown cells. $\mathbf{b}$ Vice versa, immunoprecipitation using specific antibodies and detection with WL lectin was performed as well. c Immunocytochemistry of Panc-1 COSMC knockdown cells and control cells. Left: Aberrant O-glycans, including Tn antigen, were detected using WL-FITC conjugated lectin (green). Middle left: Nucleolin was detected (red) using an anti-Nucleolin antibody (ab13541). Middle right: Nuclei were stained with DAPI (blue). Right: Overlay of Tn antigen and Nucleolin immunocytochemistry. d Nucleolin, GRP-78, Enolase and Annexin detection in the cell membrane protein fraction. Her2 antibody was used as marker for membrane fraction and GAPDH antibody was used as marker for cytoplasmic proteins 
cells revealed also cell membrane localization and a nuclear/perinuclear staining. Co-staining of $\mathrm{Tn}$ antigen and Nucleolin in COSMC knockdown cells revealed strong colocalization. Panc-1 control cells showed a perinuclear staining of Nucleolin and VVL. Altogether the staining of Panc-1 control cells was much weaker compared to Panc-1 COSMC knockdown cells (Fig. 3c).

Previously, it was shown that two of the newly identified Tn antigen carrier proteins, Nucleolin and GRP-78 also localize at the plasma membrane $[45,46]$. Therefore, we separated membrane-bound and cytosolic proteins of Panc-1 COSMC knockdown cells and control cells. Western blot analysis revealed that Nucleolin and GRP78 are membrane localized in pancreatic cancer cells, confirming previous findings. Furthermore, Annexin A2 and $\alpha$-Enolase were also detected in membrane protein fractions of Panc-1 COSMC knockdown cells and control cells. Successful cellular fractionation was confirmed using antibodies targeting Her2 and GAPDH (Fig. 3d).

\section{COSMC knockdown promotes migration and survival and} inhibits proliferation in PDAC cells in vitro.

To gain relevant insights into COSMC function in pancreatic cancer cells, we first analyzed whether COSMC might influence proliferation of Panc-1 cells. Interestingly, analysis of Panc-1 COSMC knockdown cells by MTT assay revealed a strong reduction in proliferation, compared to control cells ( $\mathrm{p}<0.001)$, whereas COSMC knockdown had no effect on proliferation in L3.6pl cells (Fig. 4a). Next, we analyzed the influence of COSMC expression on cancer cell migration in vitro. Therefore, we performed transwell assays and quantified the migratory potential of COSMC knockdown as well as corresponding control cells after $24 \mathrm{~h}$. Migration of Panc-1 COSMC knockdown cells was substantially higher compared to control cells (Fig. 4b-c) $(p<0.001)$. Additionally, migrating cells were recorded in a wound healing assay and the cell displacement rate during migration was quantified. The median displacement rate of Panc-1 COSMC knockdown cells was $154.4 \mu \mathrm{m} / \mathrm{s}$ whereas control cells showed a median displacement rate of $108.1 \mu \mathrm{m} / \mathrm{s}$ $(p<0.05)$. The displacement rate of Panc-1 COSMC knockdown cells was $0.00153 \mu \mathrm{m} / \mathrm{s}$ and that of Panc-1 control cells was $0.00095 \mu \mathrm{m} / \mathrm{s}(p<0.05)$ (representative images are shown in Fig. $4 \mathrm{~b}$ ). The meandering index of Panc-1 COSMC knockdown cells was 0.261 and 0.196 in control cells $(p<0.001)$. To analyze whether COSMC knockdown influences apoptosis in pancreatic cancer, a cleaved Caspase-3 ELISA assay was performed. Interestingly, COSMC depleted Panc-1 and L3.6pl cells showed substantially decreased apoptosis compared to corresponding control cells. Cleaved Caspase- 3 expression was determined after $24 \mathrm{~h}$ and showed a $53 \%$ reduced apoptosis rate in Panc-1 COSMC knockdown cells $(p=0.03)$.
L3.6pl COSMC knockdown cells showed a $44 \%$ reduction of apoptosis rate $(p=0.017)$ compared to control (Fig. $4 \mathrm{~d})$.

\section{Tn antigen and Nucleolin are frequently co-localized in PDAC patient specimens}

It is well known that non-malignant epithelial cells display long branched O-linked glycan structures such as core 2 and core 3 glycans that are attached, for instance to various mucins [47]. In malignant cells, a complex interplay of various glycosyltransferases/chaperones promotes a reduced expression of long branched glycans and concomitant increase truncated glycans (Tn antigen).

To analyze whether pancreatic cancer cells display such truncated glycans on the MS-based identified Nucleolin, we analyzed 43 different PDAC patient specimens using VVL-mediated detection of Tn antigen and its possible co-localization with Nucleolin using specific antibodies. To exclude possible cross-reactivity of VVL with other blood group determinants (A and $A B)$ [29], we solely analyzed PDAC specimens derived from non$\mathrm{A}$ and non-AB blood group patients. The degree of $\mathrm{Tn}$ expression and Nucleolin expression partially reflects the degree of co-localization. In fact, co-localization was determined in 3 groups: 1 . Tn/Nucleolin expression and colocalization, 2. Tn/Nucleolin expression without/minimal co-localization, 3. Minimal Tn/Nucleolin expression without/minimal co-localization. Group 1 was compared to group $2 / 3$ and named strong co-localization vs. weak co-localization. Interestingly, immunofluorescence staining of these tumor specimens showed tumors with weak or strong co-localization of Tn antigen and Nucleolin (Fig. 5a). 22 (51 \%) PDAC specimens showed weak and 21 (49 \%) PDAC specimens showed strong co-localization. Moreover, correlation of this co-localization with available clinical survival data revealed poor survival for patients with a strong co-localization compared to patients with a weak co-localization of Nucleolin and VVL in KaplanMeyer survival analysis using Log-Rank test $(p=0.037)$. Five patients in the group of weak co-localization and one patient with strong co-localization of $\mathrm{Tn}$ antigen and Nucleolin were censored, because they outlived the 1500 days follow up periode (Fig. 5b). In our study, the degree of Tn antigen and Nucleolin expression is not related to survival of patients suffering pancreatic ductal adenocarcinoma (log-rank test, $p=0.95$ and $p=0.34$ ) (Additional file 1: Figure S10 and S11).

\section{Discussion}

The discovery of $\mathrm{Tn}$ antigen was a milestone in the history of glycosciences [5]. The Tn antigen was first described in the Tn polyagglutination syndrome by Moreau et al. in a patient with hemolytic anemia [48]. The underlying mechanism was discovered 48 years later in 2005 by Ju and Cummings and was identified as a mutation of the 


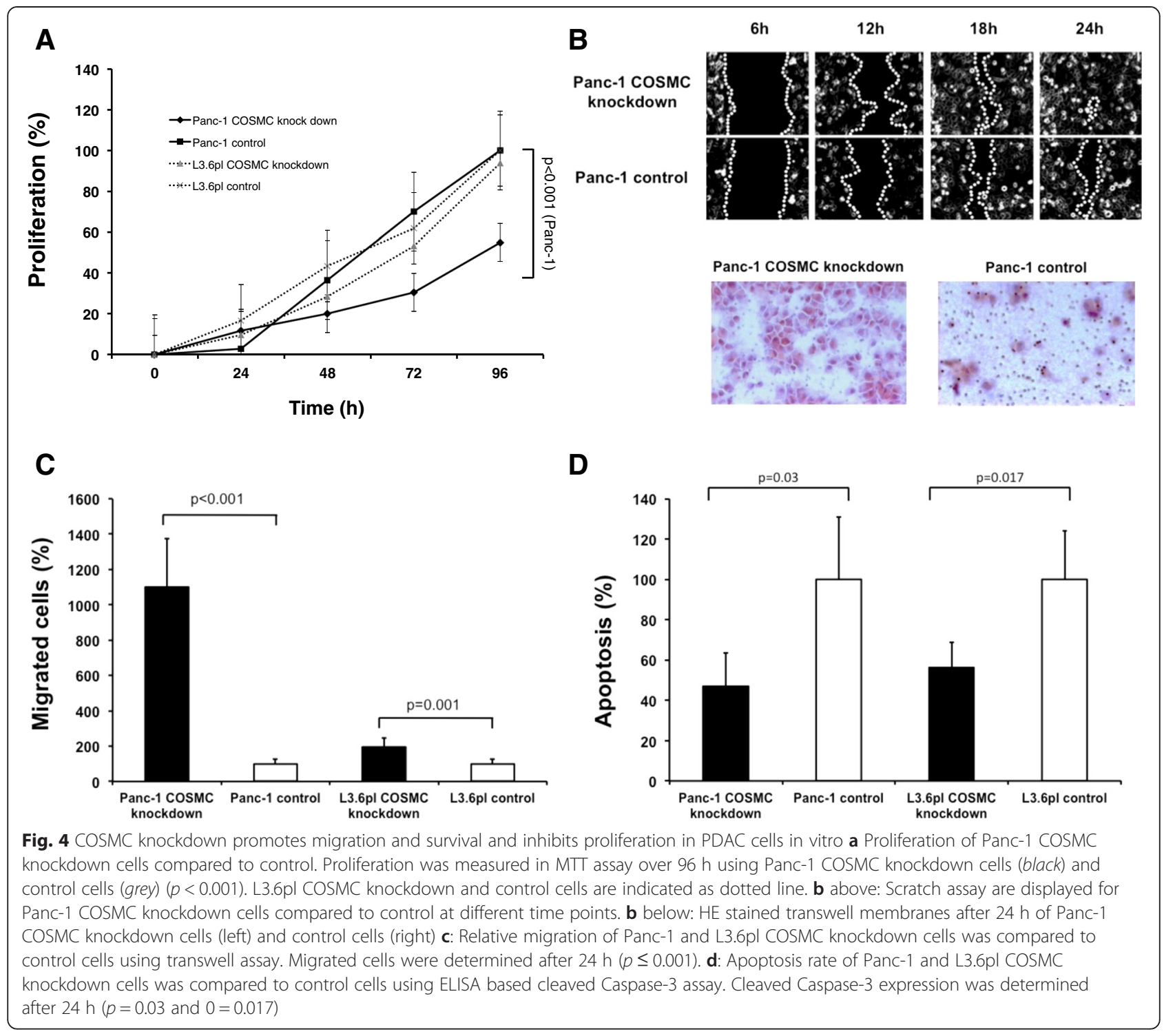

COSMC chaperone [49]. Since then, functional studies with expression of $\mathrm{Tn}$ antigen via manipulation of COSMC chaperone was possible and the knowledge on differential cancer $\mathrm{O}$-glycosylation was greatly expanded.

In this study, we examined different pancreatic cancer cell lines to give an overview of Tn antigen expression and to determine cell lines with low or moderate Tn antigen expression. We detected high molecular weight signals (150-250 kDa), indicating detection of high molecular weight proteins similar to the known mucin staining, but the Jurkat control cell line showed strong signals of lower molecular weight bands with approximately $75 \mathrm{kDa}$. On the other hand, lectins showed cell line dependent staining over a broad range with molecular weights between $<50-250 \mathrm{kDa}$. These detected differences are probably due to varying binding specificity of different lectins and antibodies regarding the amino acid back bone of Tn antigen carrying proteins [50]. In addition, the detected Western blot signals are probably not solely Tn antigen expression but also a staining of terminal presented GalNAc structures [17-22, 51]. One way of Tn antigen expression in human carcinoma cells is the loss of functional COSMC. Tn antigen expression has been shown in cervical carcinoma, melanoma and colon carcinoma cells due to somatic mutation of COSMC or absence of COSMC transcript [15]. Epigentic silencing through methylation of COSMC promotor in pancreatic carcinoma caused inactivation of $\mathrm{T}$-synthase with consecutive aberrant O-glycosylation [4]. In this study, we investigated the influence of Tn antigen expression on pancreatic carcinoma cells using a stable lentiviralmediated COSMC knockdown and detected an enrichment of aberrant O-glycans using a broad array of antibodies and lectins. 

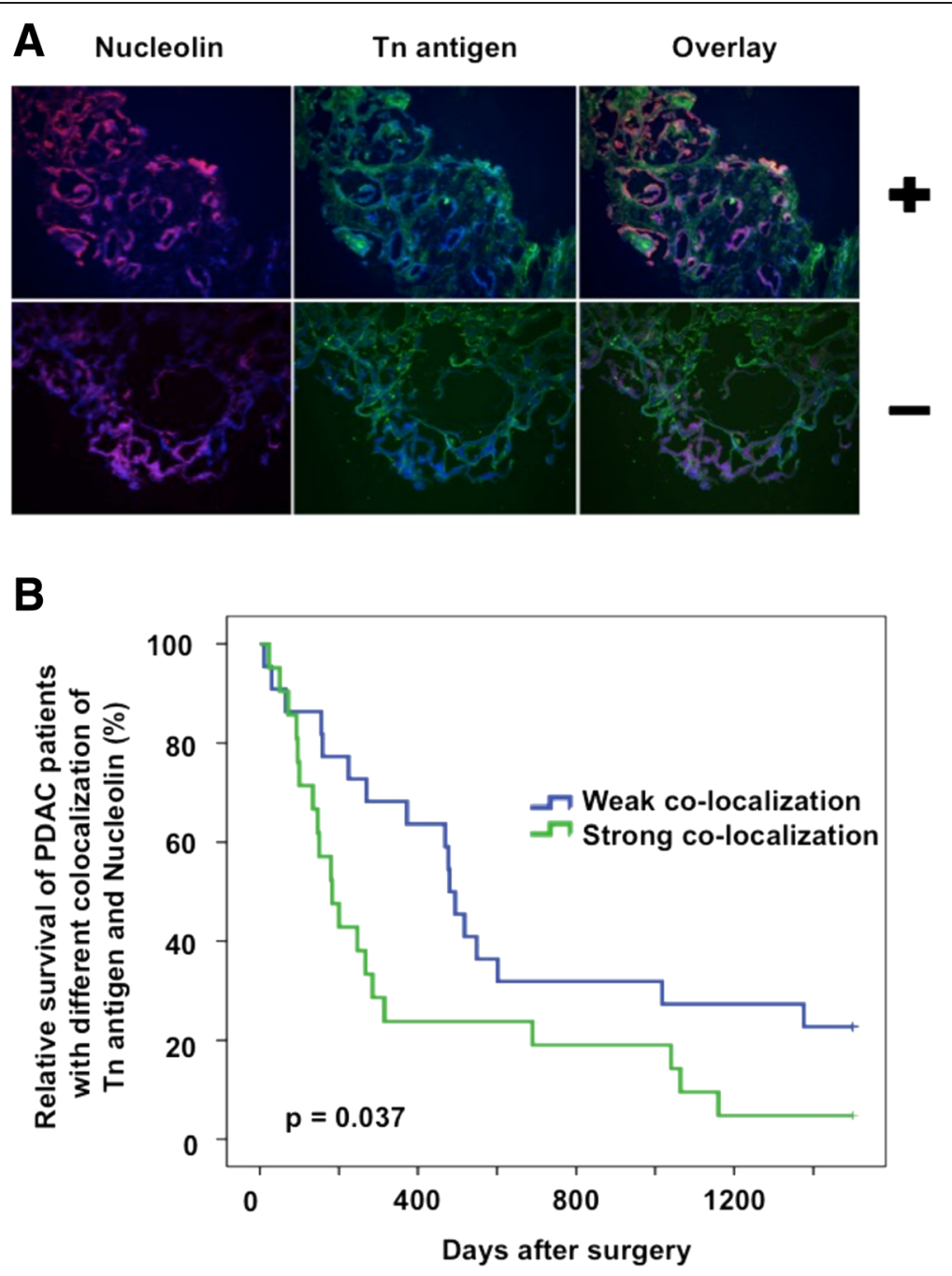

Fig. 5 Tn antigen and Nucleolin are frequently co-localized in PDAC patient specimens. a Tn antigen and Nucleolin expression in PDAC. Immunohistochemistry of patient-derived PDAC samples revealed a frequent co-expression (orange) of Tn antigen using WL-mediated staining (green) and Nucleolin staining (red). Nuclei were detected with DAPI (blue). Pictures marked with + displayed a tumor specimen with strong co-expression, whereas the tumor probe marked with - showed weak co-expression b Kaplan-Meyer survival plot with 43 PDAC patients with strong and weak co-localization of WL and Nucleolin staining $(p=0.037)$

Since GalNAc-transferases (GalNAc-Ts) catalyze the first step of O-glycosylation which results in the formation of Tn antigen, we also examined whether COSMC knockdown influences expression levels of all known human GalNAc-Ts. Interestingly, we detected substantially decreased mRNA levels for various GalNAc-Ts in COSMC knockdown cells. Down-regulation of GalNAc$\mathrm{T}$ mRNA expression after COSMC knockdown might indicate a negative feedback regulation, which reduces the expression of GalNAc-T mRNA in the presence of elevated Tn antigen levels. This might represent a novel mechanism of regulation for the activity of GalNAc-Ts, since the activity of GalNAc-Ts is known to be regulated through expression levels or by regulated relocation of GalNAc-Ts from Golgi apparatus to endoplasmic reticulum [18]. Analyzing the obtained expression results of GalNAc-Ts, we can state with certainty, that the observed changes in O-glycosylation are COSMC knockdown mediated. In contrast, T-synthase mRNA expression levels increased 2-fold in COSMC knockdown cells compared to control cells. The increased T-synthase levels might be an attempt of the cell to overcome the lack of functional T-synthase.

Using mass spectrometry, we identified 23 different OGalNAc glycosylated and abundantly expressed proteins in Panc-1 COSMC knockdown cells. Mapping of the human O-GalNAc glycoproteome has recently gained great importance using a zinc finger nuclease mediated targeting of COSMC gene [52]. Amongst several cell lines, this technology was also used in Capan-1, a 
pancreatic cancer cell line. The authors found that almost $50 \%$ of the identified glycoproteins were expressed uniquely in one cell line and each cell line contributed its own repertoire of glycoproteins. Altogether only 14 proteins were identified in all 12 cell lines and a new subset of glycoproteins was found [52]. These findings suggest distinct O-glycoproteomes for each type of cancer, however, further investigations are needed to gain insights into its possible therapeutic value.

Targeting of tumor specific O-glycoslyation is a promising treatment strategy for cancer, but faces various challenges. After Tn antigen administration, a sufficient immune and anti-tumor response in nonhuman primates was induced [53]. Thereafter, Tn antigen evolved to an important component of glycoconjugate based anti-tumor vaccines $[5,54]$. Springer and colleagues reported a successful vaccination of 16 breast cancer patients with a statistical significant better survival, however, the validity of their data cannot be determined due to the absence of several controls as well as appliance of a questionable glycoprotein preparation [55]. The treatment of prostate cancer was another focus of Tn antigen based vaccination. In a phase I clinical trial, all patients developed an immune response against Tn antigen, but only $33 \%$ achieved favorable clinical responses with decreased detection of prostate-specific antigen [56]. Long-term survival data have not been published so far, but these studies might provide a first prospect whether Tn antigen vaccination results in favorable effects in patients. Nonetheless, to provide a substantiate basis for successful vaccination with $\mathrm{Tn}$ antigen, a proper antigen expression is required.

Since the first discovery of Tn antigen, a variety of methods have been developed, mostly being dependent on either antibodies or lectins. A high number of different GalNAc-binding lectins or antibodies are available and were already successfully applied in various expression studies of human cancers, including pancreatic cancer. Unfortunately, the results of these studies showed no consistency, which might be a consequence of different binding specificities of individually used lectins and antibodies. Tn antigen binding lectins and antibodies may also cross-react with other carbohydrate antigens [51]. In addition, monoclonal antibodies recognize not only the $\mathrm{Tn}$ antigen but also depend on the individual amino acid backbone of the protein, leading to a distinct recognition pattern of $\mathrm{Tn}$ containing glycoproteins on cancer cells [50].

Altogether, pancreatic cancer has most likely its specific glycoproteome and hence the need arises for its specific detection. Here, we focused on the identification of aberrant $\mathrm{O}$-glycosylated proteins in pancreatic cancer. The proteins identified may contribute to a better understanding of the pancreatic cancer O-glycoproteome and may help to develop pancreatic cancer specific vaccinations or other therapies in future. Therefore, membrane-associated proteins were of pivotal interest, because they represent potential targets for immunotherapy. We evaluated all $23 \mathrm{O}$-glycoproteins regarding their localization in cancer, involvement in signal transduction and focused our analysis on four proteins for further characterization (Tab. 1). In this study, Tn antigen expression was confirmed for Nucleolin, GRP-78, Enolase and Annexin A2 using a VVL-based immunoprecipitation and all other identified Tn antigen carrier proteins were predicted to be highly O-glycosylated by the ISOGlyP database. Moreover, we could clearly show that Nucleolin is frequently co-localized with Tn antigen in patient-derived PDACs and strong co-localization is correlated with poor survival of the patients.

Additionally, the degree of Tn and Nucleolin expression is not related to survival of patients suffering from pancreatic ductal adenocarcinoma (log-rank test) (Additional file 1: Figure S8 and S9). To the best of our knowledge, the relation of Tn expression to survival was only reported for endometrial, colon and breast cancer $[47,57]$. The lack of correlation in pancreatic cancer is difficult to explain and is possibly caused by the biologic nature of pancreatic cancer characterized by an extremely rapid tumor progression. Therefore, the survival of patients is generally very short and an influence of $\mathrm{Tn}$ antigen expression on survival is possibly masked.

Furthermore, information regarding the biological effects of COSMC knockdown on cell growth, migration and apoptosis in pancreatic cancer is scarce. Interestingly, our analysis of COSMC knockdown cells revealed an enhanced migration and decreased apoptosis accompanied by reduced proliferation compared to control cells in vitro. In breast cancer cells, implications of sialyl-Tn antigen on adhesion, migration, proliferation and tumor growth were already investigated and showed an enhanced tumorigenesis $[58,59]$. Recently, Huang et al. detected an enhanced malignant behavior of colon cancer cells overexpressing COSMC chaperone [60], equivalent to our analysis of PDAC specimens, which showed an increased expression of COSMC and T-synthase (Additional file 1: Figure S10 and S11). Due to the large proportion of stromal tissue in PDAC, the obtained regulations in gene expression need not necessarily reflect the actual situation in cancer cells. Although in contrast to our findings, both overexpression and COSMC knockdown may lead to an enhanced expression of aberrant $\mathrm{O}$-glycans and therefore contribute to the same malignant behavior of tumor cells.

We also analyzed Tn antigen and Nucleolin expression in pancreatic cancer specimens and found a poor survival of patients with strong co-localization of Nucleolin and VVL staining, which may suggest a new role of aberrant O-glycosylated proteins as biomarkers. Many of the current clinical biomarkers display carbohydrate 
modifications, but their basis and precise structure are largely not understood, because of their molecular complexity and their unknown regulations [61].

\section{Conclusion}

In conclusion, our study demonstrates the influence of altered O-glycan ( $\mathrm{Tn} / \mathrm{STn}$ ) expression on oncogenic properties in pancreatic cancer and identifies O-GalNAc modified Nucleolin as novel prognostic marker.

\section{Material and methods}

\section{Cell culture}

Panc-1, HEK-293 T, BxPC1 and MiaPaCa 2 cell lines were maintained in DMEM and L3.6pl were maintained in RPMI, each supplemented with $10 \%(\mathrm{v} / \mathrm{v})$ FCS, and $1 \%$ $(\mathrm{v} / \mathrm{v})$ penicillin and streptomycin. Patient derived cell lines 5061, 5072 and 5167 were maintained in RPMI 1640 with Glutamax (Life Technologies) supplemented with $10 \%$ of fetal calf serum (FCS), $200 \mathrm{IU} / \mathrm{ml}$ of penicillinstreptomycin, $0.1 \mathrm{mg} / \mathrm{ml}$ gentamycin (Biochrom), $50 \mathrm{nmol} / \mathrm{ml}$ of human transferrin (Sigma-Aldrich), $0.01 \mu \mathrm{g} / \mathrm{ml}$ of bovine insulin (Sigma-Aldrich), $0.01 \mu \mathrm{g} / \mathrm{ml}$ of recombinant human epidermal growth factor (Pepro Tech), and $0.01 \mu \mathrm{g} / \mathrm{ml}$ of human basic fibroblast growth factor (Pepro Tech).

Cells were cultured at $37{ }^{\circ} \mathrm{C}$ in a humidified atmosphere containing $5 \% \mathrm{CO}_{2}$. All cell lines were used at low passage number not exceeding 30 passages.

\section{Western blot analysis and antibodies/lectins}

Total protein concentrations were measured using BCA Protein Assay (Thermo Fischer). Samples containing $30 \mu \mathrm{g}$ total amount of protein were boiled for $5 \mathrm{~min}$ in Laemmli buffer and separated by SDS PAGE under reducing conditions in 4-15\% Mini-PROTEAN TGX gels (BIO-RAD). Proteins were blotted on nitrocellulose membrane (Thermo Fischer). The membrane was blocked with 1x Carbo-Free Blocking Solution (Biozol) in TBS-T and subsequently incubated with serum (1:20) in TBS-T overnight. Tn antigen antibody (MA1-80055, clone BRIC111, Thermo Fischer), sTn antigen antibody (ABIN356328, clone STN218, antibodies online) and COSMC antibody (19254-1-AP, Proteintech) were diluted 1:250 in TBS-T. HSC70 (sc-7298), GAPDH (sc-32233,) Nucleolin (sc-8031), GRP78 (sc-1051), Alpha Enolase (sc-7455) and Annexin II (sc-9061) antibodies were purchased from Santa Cruz and diluted 1:1000. Her2 antibody (\#2165, Cell Signaling) was diluted 1:100. Vicia villosa lectin B4 (B-1235) (VVL) and Wisteria floribunda lectin (B-1355) (WFL) were purchased from Vector Laboratories and diluted 1:125. Washing was performed 5 times with TBS-T. The membrane was incubated with a specific HRP-antibody (1:1250; Life Technologies) for $1 \mathrm{~h}$ at RT. After 5 times washing with
TBS-T buffer, immunodetection was performed using enhanced chemiluminescence (GE Healthcare). Protein expression was quantified using an LAS-3000 Imager from Fuji (Raytest, Straubenhardt, Germany).

\section{Lentiviral-mediated knockdown of COSMC chaperone} pLKO.1-puro vector encoding COSMC and non-target (scrambled, SCR) shRNA were purchased from SigmaAldrich (Germany). Generation of pseudotyped lentiviruses and transduction were performed as previously described [62]. Cells transduced with COSMC shRNA were selected by addition of puromycin (Sigma-Aldrich) to culture medium with a final concentration of $2 \mathrm{mM}$ for at least one week.

\section{Immunoprecipitation and membrane protein extraction}

Total cell lysates were prepared with RIPA buffer. Lysates $(0,5 \mathrm{mg})$ were pre-cleared with $40 \mu \mathrm{l}$ of protein $\mathrm{A} /$ G-agarose beads (Santa Cruz) for $1 \mathrm{~h}$. Protein A/G-agarose beads were added to the afore mentioned antibodies and rotated at $4{ }^{\circ} \mathrm{C} 1 \mathrm{~h}$. Pre-cleared proteins and beadconjugated antibodies were mixed, rotated at $4{ }^{\circ} \mathrm{C}$ overnight, pelleted and washed five times with RIPA buffer. An equal volume of $6 x$ Laemmli buffer was added, and samples were boiled and separated by SDS-polyacrylamide gel electrophoresis. For membrane protein extraction, harvested cells were resuspended in PBS and homogenized using a dounce homogenizer. Centrifugation at $100 \mathrm{~g}, 5 \mathrm{~min}, 4{ }^{\circ} \mathrm{C}$ removed undisrupted cells a second centrifugation at $100 \mathrm{~g}, 10 \mathrm{~min}, 4{ }^{\circ} \mathrm{C}$ extracted nuclei. After centrifugation at $20000 \mathrm{~g}$ for $90 \mathrm{~min}$, at $4{ }^{\circ} \mathrm{C}$, membranes were pelleted and the supernatant contained the post membrane fraction.

\section{Real-time PCR}

Total RNA was isolated using the RNeasy Mini kit (Qiagen), reverse transcribed with Transcriptor reverse transcriptase (Roche) using an oligo-(dT) primer according to the manufacturer's protocol. The cDNA was subjected to real-time PCR amplification using primer sets for COSMC, GalNAc-transferases, T-synthase and GAPDH (Additional file 2: Table S1). Real-time PCR was prepared with Maxima SYBR Green/ROX qPCR Master Mix, $0.3 \mu \mathrm{M}$ forward and reverse primer and $750 \mathrm{ng} \mathrm{cDNA}$ and used on the Lightcycler 480 (Roche). The conditions were as follows: $95{ }^{\circ} \mathrm{C}$ for $10 \mathrm{~min}, 45$ cycles at $95{ }^{\circ} \mathrm{C}$ for $15 \mathrm{~s}$, and $60{ }^{\circ} \mathrm{C}$ for $1 \mathrm{~min}$. CT values were determined using Lightcycler 480 Software version 1.5 (Roche). All samples were analyzed in duplicates, and values of the sample copies were obtained after quantitative amplification and normalized to GAPDH using $2^{-} \Delta \Delta^{\mathrm{CT}}$ method. Each experiment was at least repeated twice. 


\section{Mass spectrometry (MS)}

O-GalNAc modified proteins were identified by MALDIMS. Protein bands were excised from Coomassie stained polyacrylamide gel and trypsin (sequencing grade, Promega) was added to each sample for $4 \mathrm{~h}$ at $37{ }^{\circ} \mathrm{C}$. Extracted peptides were mixed with the matrix solution containing $\alpha$-cyano-4-hydroxycinnamic acid, spotted for MALDI-MS measurement onto target slides, and analyzed using a matrix-assisted laser desorption/ionization time of flight (MALDI-TOF) mass spectrometer (Amersham Biosciences). All measurements were performed in the positive-ion reflective mode at an accelerating voltage of $23 \mathrm{kV}$ and delayed-pulsed ion extraction. All peptide samples were measured as monoisotopic masses. Database searches were performed using the MASCOT software from Matrix Science with carboxymethylation of cysteine and methionine oxidations as variable modifications (probability value $p<0.05$ )

\section{T-Synthase assay}

Ten $\mu$ g total protein from fresh cell lysates were directly used to determine endogenous T-synthase activity using UDP-Gal (Sigma Aldrich) as the donor and GalNAc- $\alpha$ (4-MU) (Carbosynth) as the acceptor [63]. O-Glycosidase (New England Biolabs) was used for $\mathrm{T}$ antigen cleavage and release of fluorescent 4-MU. The $50 \mu \mathrm{L}$ reaction system containing $1000 \mu \mathrm{M}$ GalNAc- $\alpha-4-(\mathrm{MU}), 500 \mu \mathrm{M}$ UDP-Gal, 20 mM MnCl2, $0.2 \%$ Triton X-100, 800 units of O-glycosidase, in $50 \mathrm{mM}$ MES-NaOH buffer ( $\mathrm{pH}$ 6.8), and $10 \mu \mathrm{g}$ total protein was placed in a black OptiPlate96 F (Perkin Elmer). Adding $100 \mu \mathrm{l} 1 \mathrm{M}$ Glycine $\mathrm{NaOH}$ (pH10) stopped reactions. Relative 4-MU fluorescence was measured (ex $355 \mathrm{~nm} / \mathrm{em} 460 \mathrm{~nm}$ ) in a FLUOstar Omega (BMG Labtech). The average value of the fluorescence intensities was calculated and the control cell line was set to $100 \%$. Error bars represent SEM.

\section{Proliferation, migration and apoptosis}

The MTT assay was used for determination of cell proliferation. Cells were washed with PBS and MTT (Sigma) working solution was added into the wells. Cells were incubated at $37^{\circ} \mathrm{C}$ for $2 \mathrm{~h}$. Absorbance of the converted MTT dye was measured at a wavelength of $490 \mathrm{~nm}$ with FLUOstar Omega (BMG Labtech).

Cell migration was examined using transwell assay and scratch/wound healing assay. Briefly, $5 \times 10^{5} / \mathrm{mL}$ cells were seeded onto a transwell insert $(8-\mu \mathrm{m}$ pore; BD Biosciences) using DMEM containing 0,1 \% FBS. The fitted culture dishes were filled with DMEM containing $10 \%$ FBS. Invaded cells were either stained after $24 \mathrm{~h}$ followed by four random views and quantification under a microscope or trypsinized and then quantified. For scratch assay, the corresponding cells were cultured to create a confluent monolayer. This monolayer was then scraped with a $200 \mu \mathrm{l}$ pipet tip to create a "scratch" and wells were rinsed. The plate was then transferred a humidified incubation chamber, and cell migration was recorded using an Improvision LiveCell Spinning Disk system. Migrating cells were then tracked using Velocity 6.1.1. to quantify the respective cell displacement rate. Cell death was measured using Cleaved Caspase-3 sandwich ELISA (Cell Signaling) according to the manufacturer. Each experiment was repeated at least three times in quadruplicates.

\section{Immunofluorescence}

Cells were cultured on coverslips, fixed with $4 \%$ formaldehyde for $10 \mathrm{~min}$, washed with PBS and afterwards blocked for $1 \mathrm{~h}$ in $1 \% \mathrm{BSA} / \mathrm{PBS}-\mathrm{T}$ at RT. The cells were then incubated with the primary antibody (Nucleolin 4E2, Abcam) over night $\left(4{ }^{\circ} \mathrm{C}\right)$ or lectin (VVL-FITC, Vector) for $1 \mathrm{~h}$ at RT and washed with PBS. After incubation with the primary antibody, a fluorescent secondary antibody (Alexa Fluor 546 rabbit anti mouse IgG, Life Technologies) was added for $1 \mathrm{~h}$ at RT. After washing with PBS, the specimens were observed under a fluorescence microscope (BIOREVO BZ-9000; Keyence) and analyzed with BZ9000 Generation II Analyzer software.

\section{Statistical analysis}

Student's $t$-Test (unpaired, 2-tailed) was calculated based on the data of at least three independent experiments. Bonferroni correction for multiple testing was performed where applicable. Results were considered significant if $p<0.05$. All error bars represent SD, unless indicated otherwise. Statistical survival analysis was performed using KaplanMeyer method. The differences between survival curves were tested using log rank test, $p<0.05$ was considered significant.

\section{Additional files}

Additional file 1: Figure S1-S11. Differential expression of Tn antigen
in human pancreatic carcinoma cell lines. Eight PDAC cell lines were
available for analysis. Western blot was performed using HPA lectin
(Fig. S1), WL lectin (Fig. S2) and sialyl Tn antibody MA1-90577 (Fig. S3).
HSC70 Western blot served as loading control. Jurkat cell line was used as
positive control for Tn antigen expression. Figure S4: Lentiviral-mediated
COSMC knockdown in Panc-1 cells. Western blotting total cell lysates of
COSMC knockdown and corresponding control cells revealed successful
down regulation of COSMC. HSC70 was used as loading control. Figure S5:
Proteins of L3.6pl COSMC knockdown and control cells were used for
Western blot with (right) and without (left) Neuraminidase treatment.
Neuraminidase treated knockdown cells showed an enhanced Tn
antigen signal, detected with WL lectin, compared to controls. Figure
S6: Immunocytochemistry was performed using WL (green) and HPA
(red) lectin for COSMC knockdown cells and control cells. Cell nuclei
were counterstained using DAPI (blue). Figure S7: Distinct enrichment of
aberrant O-glycans in Panc-1 COSMC knockdown cells. Protein precipitation
with WL lectin was performed. Precipitated proteins containing glyco
epitopes were separated using SDS-PAGE and stained with Coomassie
brilliant blue. Arrows indicate the further analyzed protein bands. Molecular


weight is indicated in KDa. Figure S8 and S9: Kaplan-Meier survival estimation was calculated for patients with weak and strong $T n$ antigen expression (Fig. S8) and weak and strong Nucleolin expression (Fig. S9). No statistical differences were detected in both analyses ( $p=0.95$ and $p=0.34$ ) using log-rank test. Figure S10: mRNA expression of COSMC and T-synthase in tumor (black bar) and control samples (white bar). Average Ct value for COSMC mRNA expression was $2.8( \pm 3.45)$ in PDACs and $5.24( \pm 1.27)$ in controls $(p=0.057)$. T-synthase expression levels showed an average Ct value of $4.8( \pm 2.45)$ in PDACs and $7.26( \pm 1.52)$ in controls $(p=0.015)$. ddCt values. Figure S11: Fold change of COSMC and T-synthase mRNA expression of tumor samples compared to controls are displayed, using the $\Delta \Delta C t$ method. Majority of the samples showed increased expression levels of analyzed genes in tumors compared to control.

Additional file 2: Table S1. Real time PCR primer. Primer were designed using either Primer3 web interface [64] or taken from the Harvard PrimerBank [65].

\section{Abbreviations}

PDAC: Pancreatic ductal adenocarcinoma; COSMC: Core 1 ß3-Gal-T-specific molecular chaperone or C1GALT1C1; T-synthase: Core 1 33-galactosyltransferase or C1GALT1; GalNAc: N-Acetylgalactosamine; MTT: 3-(4,5-dimethylthiazol-2-yl)2,5-ditetrazolium bromide; WL: Vicia villosa lectin; WFL: Wisteria floribunda agglutinin.

\section{Competing interests}

The authors declared that they have no competing interests.

\section{Authors' contributions}

BTH and GWE designed the experiment, interpreted the data and prepared the manuscript. $L S, P L, B M, F E, S H, A E G, C G, A D, A S P, H S, C W$ conducted the experiment, collected the data and helped to prepare the manuscript. JI, MJ, MB interpreted the data. All authors read and approved the final manuscript.

\section{Acknowledgements}

We thank Prof. Udo Schumacher for critical reading of the manuscript. The authors thank Petra Merkert, Ute Eicke-Kohlmorgen, Petra Schröder and Antje Heinecke for excellent technical assistance. The Roggenbuck foundation supported this work. This work was supported within the collaborative project GlycoBioM, Grant Agreement Number 259869, in Framework 7 of the European Commission and by the German Federal Ministry of Education and Research, BMBF research grant 0315500B.

\section{Author details}

'Department of General, Visceral and Thoracic Surgery, University Medical Center Hamburg-Eppendorf, Martinistrasse 52, 20246 Hamburg, Germany. ${ }^{2}$ Department of Hepatobiliary and Transplant Surgery, University Medical Center Hamburg-Eppendorf, Martinistrasse 52, 20246 Hamburg, Germany. ${ }^{3}$ Department of Clinical Chemistry, University Medical Center Hamburg-Eppendorf, Martinistrasse 52, 20246 Hamburg, Germany. ${ }^{4}$ Department of Anatomy and Experimental Morphology, University Medical Center Hamburg-Eppendorf, Martinistrasse 52, 20246 Hamburg, Germany. ${ }^{5}$ Institute for Biochemistry and Signal Transduction, University Medical Center Hamburg-Eppendorf, Martinistrasse 52, 20246 Hamburg, Germany.

\section{Received: 17 August 2014 Accepted: 12 May 2015}

\section{Published online: 29 May 2015}

\section{References}

1. Stowell SR, Ju T, Cummings RD. Protein glycosylation in cancer. Annu Rev Pathol. 2015;10:473-510.

2. Wagner KW, Punnoose EA, Januario T, Lawrence DA, Pitti RM, Lancaster K, et al. Death-receptor O-glycosylation controls tumor-cell sensitivity to the proapoptotic ligand Apo2L/TRAIL. Nat Med. 2007;13:1070-7.

3. Clement M, Rocher J, Loirand G, Le Pendu J. Expression of sialyl-Tn epitopes on beta1 integrin alters epithelial cell phenotype, proliferation and haptotaxis. J Cell Sci. 2004;117:5059-69.

4. Radhakrishnan P, Dabelsteen S, Madsen FB, Francavilla C, Kopp KL, Steentoft C, et al. Immature truncated O-glycophenotype of cancer directly induces oncogenic features. Proc Natl Acad Sci U S A. 2014;111:E4066-75.
5. Ju T, Otto VI, Cummings RD. The Tn antigen-structural simplicity and biological complexity. Angew Chem Int Ed Engl. 2011;50:1770-91.

6. Itzkowitz S, Kjeldsen T, Friera A, Hakomori S, Yang US, Kim YS. Expression of $\mathrm{Tn}$, sialosyl Tn, and T antigens in human pancreas. Gastroenterology. 1991;100:1691-700.

7. Kim GE, Bae HI, Park HU, Kuan SF, Crawley SC, Ho JJ, et al. Aberrant expression of MUC5AC and MUC6 gastric mucins and sialyl Tn antigen in intraepithelial neoplasms of the pancreas. Gastroenterology. 2002;123:1052-60.

8. Terada $T$, Nakanuma Y. Expression of mucin carbohydrate antigens ( $T, \mathrm{Tn}$ and sialyl Tn) and MUC-1 gene product in intraductal papillary-mucinous neoplasm of the pancreas. Am J Clin Pathol. 1996;105:613-20.

9. Motoo Y, Kawakami H, Watanabe H, Satomura Y, Ohta H, Okai T, et al. Serum sialyl-Tn antigen levels in patients with digestive cancers. Oncology. 1991;48:321-6.

10. Nanashima A, Yamaguchi H, Nakagoe T, Matsuo S, Sumida Y, Tsuji T, et al. High serum concentrations of sialyl Tn antigen in carcinomas of the biliary tract and pancreas. J Hepatobiliary Pancreat Surg. 1999;6:391-5.

11. Springer GF. Immunoreactive $T$ and Tn epitopes in cancer diagnosis, prognosis, and immunotherapy. J Mol Med (Berl). 1997;75:594-602.

12. Tsuchiya A, Kanno M, Kawaguchi T, Endo Y, Zhang GJ, Ohtake T, et al. Prognostic relevance of Tn expression in breast cancer. Breast Cancer. 1999;6:175-80.

13. Ju T, Cummings RD. A unique molecular chaperone Cosmc required for activity of the mammalian core 1 beta 3-galactosyltransferase. Proc Natl Acad Sci U S A. 2002;99:16613-8.

14. Schietinger A, Philip M, Yoshida BA, Azadi P, Liu H, Meredith SC, et al. A mutant chaperone converts a wild-type protein into a tumor-specific antigen. Science. 2006;314:304-8.

15. Ju T, Lanneau GS, Gautam T, Wang Y, Xia B, Stowell SR, et al. Human tumor antigens $T n$ and sialyl Tn arise from mutations in Cosmc. Cancer Res. 2008;68:1636-46.

16. Mi R, Song L, Wang $Y$, Ding $X$, Zeng J, Lehoux $S$, et al. Epigenetic silencing of the chaperone Cosmc in human leukocytes expressing tn antigen. J Biol Chem. 2012;287:41523-33.

17. Brooks SA, Carter TM, Bennett EP, Clausen H, Mandel U. Immunolocalisation of members of the polypeptide $\mathrm{N}$-acetylgalactosaminyl transferase (ppGalNAc-T) family is consistent with biologically relevant altered cell surface glycosylation in breast cancer. Acta Histochem. 2007;109:273-84.

18. Gill DJ, Clausen H, Bard F. Location, location, location: new insights into O-GalNAc protein glycosylation. Trends Cell Biol. 2011;21:149-58.

19. Guda K, Moinova H, He J, Jamison O, Ravi L, Natale L, et al. Inactivating germ-line and somatic mutations in polypeptide $\mathrm{N}$ acetylgalactosaminyltransferase 12 in human colon cancers. Proc Natl Acad Sci U S A. 2009;106:12921-5.

20. Guo JM, Chen HL, Wang GM, Zhang YK, Narimatsu H. Expression of UDPGalNAc:polypeptide N-acetylgalactosaminyltransferase-12 in gastric and colonic cancer cell lines and in human colorectal cancer. Oncology. 2004;67:271-6.

21. Park JH, Katagiri T, Chung S, Kijima K, Nakamura Y. Polypeptide $\mathrm{N}$-acetylgalactosaminyltransferase 6 disrupts mammary acinar morphogenesis through O-glycosylation of fibronectin. Neoplasia. 2011;13:320-6.

22. Taniuchi K, Cerny RL, Tanouchi A, Kohno K, Kotani N, Honke K, et al. Overexpression of GalNAc-transferase GalNAc-T3 promotes pancreatic cancer cell growth. Oncogene. 2011;30:4843-54.

23. Mortezai N, Behnken HN, Kurze AK, Ludewig P, Buck F, Meyer B, et al. Tumor-associated Neu5Ac-Tn and Neu5Gc-Tn antigens bind to C-type lectin CLEC10A (CD301, MGL). Glycobiology. 2013;23:844-52.

24. Nollau P, Wolters-Eisfeld G, Mortezai N, Kurze AK, Klampe B, Debus A, et al. Protein domain histochemistry (PDH): binding of the carbohydrate recognition domain (CRD) of recombinant human glycoreceptor CLEC10A (CD301) to formalin-fixed, paraffin-embedded breast cancer tissues. J Histochem Cytochem. 2013;61:199-205.

25. Saeland E, van Vliet SJ, Backstrom M, van den Berg VC, Geijtenbeek TB, Meijer GA, et al. The C-type lectin MGL expressed by dendritic cells detects glycan changes on MUC1 in colon carcinoma. Cancer Immunol Immunother. 2007;56:1225-36.

26. Grigalevicius S, Chierici S, Renaudet O, Lo-Man R, Deriaud E, Leclerc C, et al. Chemoselective assembly and immunological evaluation of multiepitopic glycoconjugates bearing clustered Tn antigen as synthetic anticancer vaccines. Bioconjug Chem. 2005;16:1149-59.

27. Welinder C, Baldetorp B, Borrebaeck C, Fredlund BM, Jansson B. A new murine IgG1 anti-Tn monoclonal antibody with in vivo anti-tumor activity. Glycobiology. 2011;21:1097-107. 
28. Miles D, Roche H, Martin M, Perren TJ, Cameron DA, Glaspy J, et al. Phase III multicenter clinical trial of the sialyl-TN (STn)-keyhole limpet hemocyanin (KLH) vaccine for metastatic breast cancer. Oncologist. 2011;16:1092-100.

29. Hofmann BT, Stehr A, Dohrmann T, Gungor C, Herich L, Hiller J, et al. $\mathrm{ABO}$ blood group IgM isoagglutinins interact with tumor-associated Oglycan structures in pancreatic cancer. Clin Cancer Res. 2014;20:6117-26.

30. Siegel R, Naishadham D, Jemal A. Cancer statistics, 2012. CA Cancer J Clin. 2012;62:10-29.

31. Kalinina T, Gungor C, Thieltges S, Moller-Krull M, Penas EM, Wicklein D, et al. Establishment and characterization of a new human pancreatic adenocarcinoma cell line with high metastatic potential to the lung. BMC Cancer. 2010;10:295.

32. Gungor C, Zander H, Effenberger KE, Vashist YK, Kalinina T, Izbicki JR, et al. Notch signaling activated by replication stress-induced expression of midkine drives epithelial-mesenchymal transition and chemoresistance in pancreatic cancer. Cancer Res. 2011;71:5009-19.

33. Steentoft C, Vakhrushev SY, Vester-Christensen MB, Schjoldager KT, Kong Y, Bennett EP, et al. Mining the O-glycoproteome using zinc-finger nuclease-glycoengineered SimpleCell lines. Nat Methods. 2011;8:977-82.

34. Kato K, Takeuchi H, Ohki T, Waki M, Usami K, Hassan H, et al. A lectin recognizes differential arrangements of O-glycans on mucin repeats. Biochem Biophys Res Commun. 2008;371:698-701.

35. Carpentier M, Morelle W, Coddeville B, Pons A, Masson M, Mazurier J, et al. Nucleolin undergoes partial $\mathrm{N}$ - and O-glycosylations in the extranuclear cell compartment. Biochemistry. 2005;44:5804-15.

36. Cappello P, Tomaino B, Chiarle R, Ceruti P, Novarino A, Castagnoli C, et al. An integrated humoral and cellular response is elicited in pancreatic cancer by alpha-enolase, a novel pancreatic ductal adenocarcinoma-associated antigen. Int J Cancer. 2009;125:639-48.

37. Ortiz-Zapater E, Peiro S, Roda O, Corominas JM, Aguilar S, Ampurdanes C, et al. Tissue plasminogen activator induces pancreatic cancer cell proliferation by a non-catalytic mechanism that requires extracellular signal-regulated kinase 1/2 activation through epidermal growth factor receptor and annexin A2. Am J Pathol. 2007;170:1573-84.

38. Peng L, Liang J, Wang H, Song X, Rashid A, Gomez HF, et al. High levels of nucleolar expression of nucleolin are associated with better prognosis in patients with stage II pancreatic ductal adenocarcinoma. Clin Cancer Res. 2010;16:3734-42

39. Rauschert N, Brandlein S, Holzinger E, Hensel F, Muller-Hermelink HK, Vollmers HP. A new tumor-specific variant of GRP78 as target for antibody-based therapy. Lab Invest. 2008;88:375-86.

40. Hajjar KA, Guevara CA, Lev E, Dowling K, Chacko J. Interaction of the fibrinolytic receptor, annexin II, with the endothelial cell surface. Essential role of endonexin repeat 2. J Biol Chem. 1996;271:21652-9.

41. Hsiao KC, Shih NY, Fang HL, Huang TS, Kuo CC, Chu PY, et al. Surface alpha-enolase promotes extracellular matrix degradation and tumor metastasis and represents a new therapeutic target. PLoS One. 2013;8, e69354.

42. Miao YR, Eckhardt BL, Cao Y, Pasqualini R, Argani P, Arap W, et al. Inhibition of established micrometastases by targeted drug delivery via cell surface-associated GRP78. Clin Cancer Res. 2013;19:2107-16.

43. Myrvang HK, Guo X, Li C, Dekker LV. Protein interactions between surface annexin A2 and S100A10 mediate adhesion of breast cancer cells to microvascular endothelial cells. FEBS Lett. 2013;587:3210-5.

44. Gerken TA, Jamison O, Perrine $C L$, Collette JC, Moinova H, Ravi L, et al. Emerging paradigms for the initiation of mucin-type protein O-glycosylation by the polypeptide GalNAc transferase family of glycosyltransferases. J Biol Chem. 2011;286:14493-507.

45. Arap MA, Lahdenranta J, Mintz PJ, Hajitou A, Sarkis AS, Arap W, et al. Cell surface expression of the stress response chaperone GRP78 enables tumor targeting by circulating ligands. Cancer Cell. 2004;6:275-84.

46. Hovanessian AG, Soundaramourty C, El Khoury D, Nondier I, Svab J, Krust B. Surface expressed nucleolin is constantly induced in tumor cells to mediate calcium-dependent ligand internalization. PLoS One. 2010;5:e15787.

47. Brockhausen I. Mucin-type O-glycans in human colon and breast cancer: glycodynamics and functions. EMBO Rep. 2006;7:599-604.

48. Moreau R, Dausset J, Bernard J, Moullec J. Acquired hemolytic anemia with polyagglutinability of erythrocytes by a new factor present in normal blood. Bull Mem Soc Med Hop Paris. 1957;73:569-87.

49. Ju T, Cummings RD. Protein glycosylation: chaperone mutation in Tn syndrome. Nature. 2005;437:1252.
50. Mazal D, Lo-Man R, Bay S, Pritsch O, Deriaud E, Ganneau C, et al. Monoclonal antibodies toward different Tn-amino acid backbones display distinct recognition patterns on human cancer cells. Implications for effective immuno-targeting of cancer. Cancer Immunol Immunother. 2013;62:1107-22.

51. Li Q, Anver MR, Butcher DO, Gildersleeve JC. Resolving conflicting data on expression of the Tn antigen and implications for clinical trials with cancer vaccines. Mol Cancer Ther. 2009;8:971-9.

52. Steentoft C, Vakhrushev SY, Joshi HJ, Kong Y, Vester-Christensen MB, Schjoldager KT, et al. Precision mapping of the human O-GalNAC glycoproteome through SimpleCell technology. EMBO J. 2013;32:1478-88.

53. Lo-Man R, Vichier-Guerre S, Perraut R, Deriaud E, Huteau V, BenMohamed L, et al. A fully synthetic therapeutic vaccine candidate targeting carcinomaassociated Tn carbohydrate antigen induces tumor-specific antibodies in nonhuman primates. Cancer Res. 2004;64:4987-94.

54. Tarp MA, Clausen H. Mucin-type O-glycosylation and its potential use in drug and vaccine development. Biochim Biophys Acta. 2008;1780:546-63.

55. Springer GF, Desai PR, Tegtmeyer H, Spencer BD, Scanlon EF. Pancarcinoma $\mathrm{T} / \mathrm{Tn}$ antigen detects human carcinoma long before biopsy does and its vaccine prevents breast carcinoma recurrence. Ann N Y Acad Sci. 1993;690:355-7.

56. Slovin SF, Ragupathi G, Fernandez C, Diani M, Jefferson MP, Wilton A, et al. A polyvalent vaccine for high-risk prostate patients: "are more antigens better?". Cancer Immunol Immunother. 2007;56:1921-30.

57. Ohno S, Ohno Y, Nakada H, Suzuki N, Soma G, Inoue M. Expression of Tn and sialyl-Tn antigens in endometrial cancer: its relationship with tumorproduced cyclooxygenase-2, tumor-infiltrated lymphocytes and patient prognosis. Anticancer Res. 2006;26:4047-53.

58. Julien S, Adriaenssens E, Ottenberg K, Furlan A, Courtand G, VercoutterEdouart AS, et al. ST6GalNAc I expression in MDA-MB-231 breast cancer cells greatly modifies their O-glycosylation pattern and enhances their tumourigenicity. Glycobiology. 2006;16:54-64.

59. Julien S, Lagadec C, Krzewinski-Recchi MA, Courtand G, Le Bourhis X, Delannoy P. Stable expression of sialyl-Tn antigen in T47-D cells induces a decrease of cell adhesion and an increase of cell migration. Breast Cancer Res Treat. 2005;90:77-84.

60. Huang J, Che MI, Lin NY, Hung JS, Huang YT, Lin WC, et al. The molecular chaperone Cosmc enhances malignant behaviors of colon cancer cells via activation of Akt and ERK. Mol Carcinog. 2014;53 Suppl 1:E62-71.

61. Reis CA, Osorio H, Silva L, Gomes C, David L. Alterations in glycosylation as biomarkers for cancer detection. J Clin Pathol. 2010;63:322-9.

62. Ewald F, Grabinski N, Grottke A, Windhorst S, Norz D, Carstensen L, et al. Combined targeting of AKT and mTOR using MK-2206 and RAD001 is synergistic in the treatment of cholangiocarcinoma. Int J Cancer. 2013;133:2065-76.

63. Ju T, Xia B, Aryal RP, Wang W, Wang $Y$, Ding $X$, et al. A novel fluorescent assay for T-synthase activity. Glycobiology. 2011;21:352-62.

64. Koressaar T, Remm M. Enhancements and modifications of primer design program Primer3. Bioinformatics. 2007;23:1289-91.

65. Wang X, Spandidos A, Wang H, Seed B. PrimerBank: a PCR primer database for quantitative gene expression analysis, 2012 update. Nucleic Acids Res. 2012;40:D1144-9.

\section{Submit your next manuscript to BioMed Central and take full advantage of:}

- Convenient online submission

- Thorough peer review

- No space constraints or color figure charges

- Immediate publication on acceptance

- Inclusion in PubMed, CAS, Scopus and Google Scholar

- Research which is freely available for redistribution 